\title{
Neural mobilization and static stretching in an experimental sciatica model - an experimental study
}

\section{Mobilização neural e alongamento estático em um modelo experimental de ciatalgia - estudo experimental}

\author{
Gladson R. F. Bertolini', Taciane S. Silva', Danilo L. Trindade', Adriano P. Ciena', Alberito R. Carvalho',2
}

\begin{abstract}
Objective: To verify the effectiveness of neural mobilization and static stretching in reducing pain in rats submitted to experimental sciatica. Methods: The rats $(n=23)$ were divided into three groups: sham ( $S G / n=8)$, without intervention; stretching (STCG/n=8), treated with static stretching; and neural mobilization $(\mathrm{NMG} / \mathrm{n}=7)$, treated with neural mobilization. The animals underwent an experimental model of sciatica by compression of the right ischiatic nerve with catgut suture thread. There were five consecutive sessions of treatment that began on the third day after lesion. The pain caused by the sciatica was evaluated by a functional incapacitation test that measured paw elevation time (PET), and values over 10s were indicative of pain. PET was measured at the following moments: before the lesion (M1), immediately before (M2) and after the first session (M3), immediately after the last session (M4) and 24h after the last session (M5). ANOVA was applied with repeated measures and unrepeated measures for intra- and inter-group comparison, respectively. Results: In the SG, post-lesion PETs were greater than M1 $(p<0.001)$, suggesting persistence of pain. In the STCG, post-lesion PETS were greater than $M 1(p<0.001)$, but lower when comparing M3 vs. M4 $(p<0.05)$ and M3 vs. M5 $(p<0.01)$ suggesting the effectiveness of the treatment. In NMG, M2, M3 $(p<0.001)$ and M4 $(p<0.05)$ were greater in relation to $M 1$, but not M5, showing that this treatment reestablished the normal PET values. Conclusion: Both forms of therapy were effective in reducing pain, with neural mobilization being the more effective of the two.
\end{abstract}

Key words: sciatica; physical therapy modalities; neuralgia.

\section{Resumo}

Objetivo: Verificar a eficácia da mobilização neural e do alongamento estático na redução da dor em ratos submetidos à ciática experimental. Métodos: Os ratos ( $n=23$ ) foram divididos em três grupos: simulacro ( $G S / n=8)$, sem intervenção; alongamento (GAL/ $n=8)$, tratados com alongamento estático; e mobilização neural $(G M N / n=7)$, tratados com mobilização neural. Submeteram-se os animais a um modelo experimental de ciática, comprimindo o nervo isquiático direito com fio de catgut. Realizaram-se cinco sessões consecutivas de tratamento que se iniciaram no terceiro dia pós-lesão. Avaliou-se a dor, provocada pela ciática, pelo teste de incapacidade funcional que mensurava o tempo de elevação da pata (TEP) do animal, e valores maiores que 10 segundos eram indicativos de dor. O TEP foi mensurado nos momentos: antes da lesão (M1), imediatamente antes (M2), após a $1^{\text {a }}$ sessão (M3), imediatamente após a última sessão (M4) e 24 horas após a última sessão (M5). Aplicou-se ANOVA com medidas repetidas e não repetidas para análise intra e intergrupos, respectivamente. Resultados: No GS, os TEPs no pós-lesão foram maiores que $M 1(p<0,001)$, sugerindo persistência da dor. No GAL, os TEPs foram maiores no pós-lesão em relação a $M 1$ ( $p<0,001)$, mas diminuiu nas comparações M3xM4 $(p<0,05)$ e M3XM5 $(p<0,01)$ sugerindo a eficácia do tratamento. No GMN, M2, M3 $(p<0,001)$ e M4 ( $p<0,05)$ foram maiores em relação a M1, mas M5 não, mostrando que este tratamento restabeleceu os valores normais de TEP. Conclusão: As duas formas de terapia foram eficazes na redução da dor, sendo a mobilização neural mais efetiva.

Palavras-Chave: ciática; modalidades de fisioterapia; neuralgia.

Received: 03/09/2008 - Revised: 18/12/2008 - Accepted: 05/05/2009

\footnotetext{
${ }^{1}$ Laboratory for the Study of Injuries and Physical Therapy Resource, Universidade Estadual do Oeste do Paraná (UNIOESTE), Cascavel (PR), Brazil 


\section{Introduction $: \therefore$.}

Sciatica can be considered a referred pain syndrome in which the pain is reported in the lower limb in the absence of any local disturbance ${ }^{1}$. This condition is due to ischiatic nerve compression, the most common cause being herniated disk. Other causes that can be cited are degenerative spine disease, infections, traumatic posterior hip dislocation, congenital anomalies ${ }^{2}$, piriformis syndrome ${ }^{3}$ and lumbar spinal canal stenosis. The symptoms include low back pain, pain along the nerve, sensorial disturbances and weakness of the lower limb muscles innervated by the ischiatic nerve $e^{4}$.

The rehabilitation methods of conditions that cause back pain are quite controversial in the literature, and the studies that attempt to determine the best strategies for intervention are still inconclusive ${ }^{5}$. Stretching exercises are rarely described in detail in these studies, but it seems that static stretching is the most commonly employed ${ }^{6}$. In practice, static stretching is widely used, and it is considered a safe method that aims to lengthen a muscle at a tension level that can be tolerated for a given time ${ }^{7}$. Not only the disagreements relevant to the treatment of lumbar disorders, stretching itself as a specific technique is reported in the literature as a source of debate ${ }^{8}$, which justifies considering stretching as a variable of study.

Sciatica due to nerve compression ${ }^{9}$, originating from a neurapraxic-type injury, is characterized by a decrease in nerve conductivity and causes selective atrophy of the muscle fibers innervated by compromised motor neurons ${ }^{10}$. Neural provocation tests are conducted with the objective of aiding in the diagnosis of nerve compression syndromes ${ }^{11}$, and they are adapted for the treatment of these syndromes (neural mobilization), with varied results reported in the literature ${ }^{12-15}$.

The principle of neural mobilization is that changes in the mechanics or the physiology of the nervous system can result in other system dysfunctions or dysfunctions of the musculoskeletal structures that receive its innervations. The neural mobilization technique is used to regain the movement and elasticity of the nervous system, with the objective of improving neurodynamics and reestablishing axoplasmic flow, thus restoring nerve tissue homeostasis, which promotes the return to its normal functions. The technique is also used to regain joint flexibility ${ }^{14}$. While both neural mobilization and static stretching are therapeutic resources with questionable results presented in the literature, the aim of this study was to verify the effectiveness of neural mobilization and static stretching in reducing pain in rats submitted to an experimental sciatica model.

\section{Methods : :}

\section{Experimental groups}

Twenty-three Wistar rats, weighing a mean $347.00 \pm 31.68 \mathrm{~g}$, were used for the experimental model. The animals were housed (three to four per cage) at a controlled temperature of $25 \pm 1^{\circ} \mathrm{C}$ and on a $12 \mathrm{~h}$ light/dark cycle with free access to food and water.

The animals were divided into three groups:

- Sham Group (SG, $\mathrm{n}=8$ ) - submitted to sciatica in the right limb and to sham treatment;

- Stretching Group (STCG, $\mathrm{n}=8$ ) - submitted to sciatica and treated with static stretching;

- Neural Mobilization (NMG, $\mathrm{n}=7$ ) - submitted to sciatica and treated with neural mobilization.

All of the experiments in the present study were conducted according to international ethics regulations for animal experiments ${ }^{16}$. The study was approved by the Ethics Committee on Animal Experimentation and Practical Classes of Universidade Estadual do Oeste do Paraná, process number 0109.

\section{Experimental lesion protocol}

Anesthesia was induced with ketamine $(95 \mathrm{mg} / \mathrm{kg})$ and xylazine $(12 \mathrm{mg} / \mathrm{kg})$ via the intraperitoneal route. Experimental neuropathy in rats was produced by surgery, according to a method previously described by Bennett and $\mathrm{Xie}^{17}$. Briefly, the right ischiatic nerve was exposed at the mid-thigh level and the nerve was then constricted with four loose ligatures using chromic catgut 4.0 spaced at about $1 \mathrm{~mm}$, reproducing chronic pain. Soon after, suturing was performed using plane suture.

\section{Functional incapacitation test}

The functional incapacity test was accomplished using a rotating metal cylinder, and a computer program connected to a metallic boot adapted to the animal's paw, as originally described by Tonussi and Ferreira ${ }^{18}$.

The rats were placed in the cylinder for 1 minute. A computer-assisted device measured the total time that the right hind paw was not in contact with the surface of the cylinder (paw elevation time; PET). The left hind paw was also connected by a boot, but without information transfer to the computer ${ }^{18}$.

The experiment began with the rats training in the cylinder. The following day, the time values of the normal gait were logged. PET was measured at the following moments: before the lesion (M1); immediately before (M2) and after (M3) the $1^{\text {st }}$ treatment session that began on the $3^{\text {rd }}$ day after 
compression; immediately after the last session (M4); and $24 \mathrm{~h}$ after the last session (M5). There was a total of five consecutive sessions at the same time of day on subsequent days. After the final data collection, the animals were sacrificed by means of decapitation in guillotine. Animals without changes normally maintain paw elevation for approximately 10 seconds during gait, and animals with pain due to ischiatic nerve compression present a higher $\mathrm{PET}^{19}$.

\section{Treatment protocols}

For the treatment protocols, the animals were sedated with ethyl ether, and the treatment was applied to the right hind limb, in the three groups. In the STCG, the treatment protocol was accomplished with the animal in dorsal decubitus, hip flexed at approximately $70^{\circ}$, maximum knee extension and ankle dorsiflexion until resistance to the motion was felt; the position was then maintained for one minute. In the protocol used for the NMG, the animal was positioned in similar way to the STCG, however the ankle was moved passively in plantarflexion and dorsiflexion, with approximately 30 movements in one minute. This intervention was adapted from the intervention recommended for ischiatic nerve stretching in humans ${ }^{20}$. The position used for both interventions can be seen in Figure 1. In the SG, the animal was also sedated and positioned in dorsal decubitus, but only the hip was maintained in flexion of about $70^{\circ}$, with free knee and ankle joints.

\section{Statistical analysis}

The results were expressed by means of descriptive statistics (mean and standard deviation) and analyzed by one-way ANOVA and repeated measures ANOVA, for inter- and intragroup comparison, respectively. Tukey post-hoc tests were also used. Differences were considered statistically significant at the $\mathrm{p}<0.05$ level.

\section{Results $: \because$.}

For the results related to PET, the SG showed a significant increase after the lesion (M2) compared to the moment before the lesion (M1), and this increase continued at every appraised moment. When comparing the post-lesion value (M2) to the subsequent moments (M3, M4 and M5), there was significant PET decrease, suggesting the persistence of pain (Figure 2). For the STCG, as in the SG, there was significant PET increase when comparing the moment before the lesion (M1) to the subsequent ones (M2, M3, M4 and M5). In contrast, when comparing the moment after lesion (M2) with the subsequent ones,

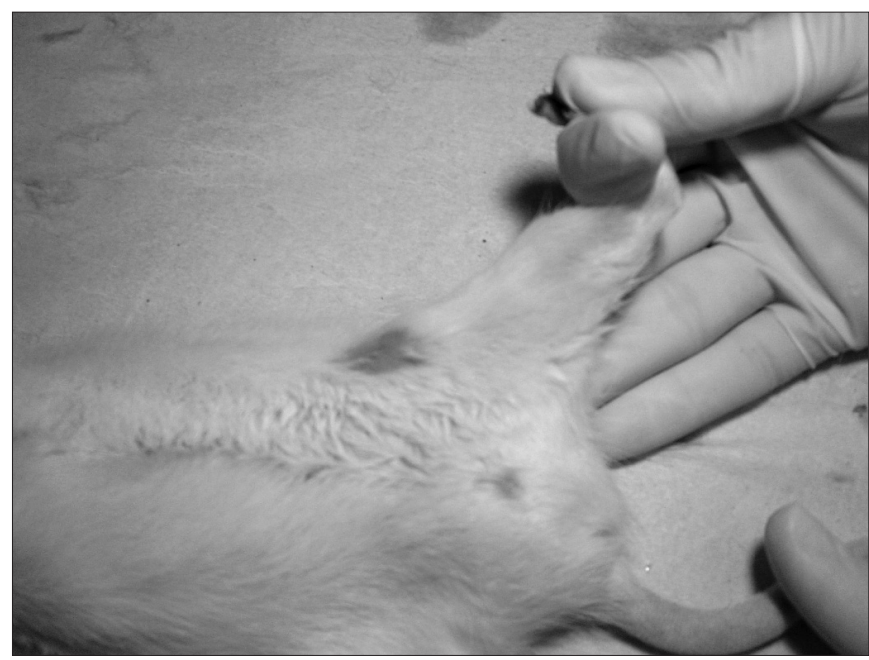

Figure 1. Positioning the animal to receive treatment with hip inflexion, knee extension and ankle dorsiflexion.

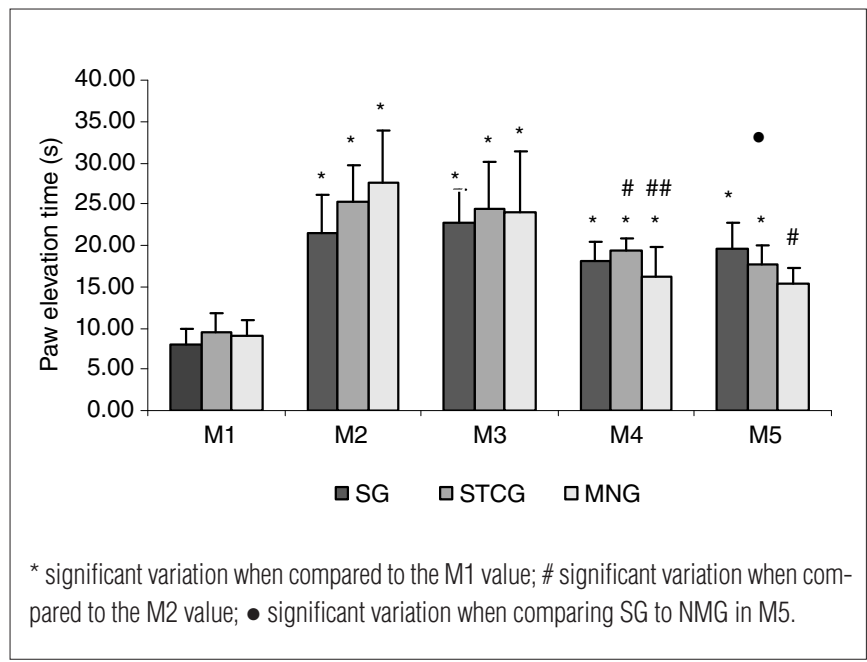

Figure 2. Variation in paw elevation times, in seconds, for: the sham group (SG), stretching group (STCG) and neural mobilization group (NMG); at the moments: before lesion (M1), on the $3^{\text {rd }}$ day after the lesion and before the initial treatment (M2), on the $3^{\text {rd }}$ day after the lesion and after the first treatment (M3), after the last day of therapy (M4), and 24 hours after the last day of therapy (M5).

there was a significant decrease after the last treatment (M4) and after 24 hours of the last treatment (M5) suggesting that, although the pain has persisted after the lesion, it diminished but did not disappear completely (Figure 2).

Finally, for the NMG, there was also significant difference when comparing the moment before lesion (M1) to the moments after lesion (M2), immediately after treatment and after the last treatment (M3 and M4, respectively), but not when compared to the moment 24 hours after the last treatment (M5). This shows that there was pain provocation after the lesion, however due to the intervention, there was pain remission. As in the STCG, there was a significant decrease when comparing the moment after lesion (M3) to the moment after 
the last treatment (M4) and to the moment 24 hours after the last treatment (M5) (Figure 2).

\section{Discussion $: \therefore$.}

In the present study, the aim was to analyze and compare two techniques of kinesiotherapy for the pain associated with an experimental sciatica model. To achieve that, neural mobilization and static stretching were used because the literature indicates contrasting results for pain processes due to peripheral nerve lesion ${ }^{12-15}$.

Hall and Elvey ${ }^{21}$ contraindicate stretching as therapy for nerve lesions, and they indicate gentle oscillatory movements in the anatomical structures around the affected nerve tissue. They mention that when the nerve fascicle is stretched, its cross-sectional area is reduced, intra-fascicular pressure increases, nerve fibers are compressed and microcirculation is compromised; and the pressure received by the nerve will affect the edema and the demyelination. Given that neural mobilization consists of short oscillatory movements and that in the present study this technique was more effective than static stretching, it is suggested that the tension maintained by static stretching may be less beneficial to nerve integrity than short, repetitive stress. However, future studies that make a comparison between intra-fascicular pressure caused by static stretching and by neural mobilization are needed before this hypothesis can be accepted.

Kikukawa et al. ${ }^{22}$ investigated the acute changes in the axonal cytoskeleton after one hour of moderate stretching $(2 \mathrm{~N})$ in the brachial plexus nerves of rats. They reported that the microtubules were depolymerized by stretching, which can affect axonal nerve transport. Kobayashi et al. ${ }^{23}$ evaluated changes in blood flow with the straight-leg-raising test in 12 patients before and after microdiscectomy and found that during the test there was flow reduction. They mention that the adhesions caused by inflammatory reactions between the lesion and the nerve root could reduce nerve mobility during limb movement, resulting in changes in flow with subsequent hypoxia, edema and demyelinisation.

However, Cleland et al. ${ }^{12}$ investigated the use of passive stretching, similar to the "slump test", in patients with low back pain, and with a positive test result. They used a visual analog scale (VAS), a pain diagram and the Oswestry Disability Index for evaluation; the patients were treated for three weeks, twice a week. At the end, the patients submitted to treatment with lumbar mobilization and exercises as well as the stretching slump had improvements in disability, pain and centralization of symptoms.

The present study also found that the group submitted to one minute of daily static stretching for one week had improvement in pain because the PET values on the last day of treatment and 24 hours later were higher than the values after the lesion. That was not the case for the sham group. In the sham group, there was a significant PET increase in the post-lesion evaluations, and at every other moment there was a significant PET decrease, indicating the presence of pain during gait.

Considering the evidence for and against the use of static stretching in peripheral nerve disorders and comparing it to the positive findings of the present study, it seems that one of the sources of bias in the studies is the tension imposed on the nerve, given that there is no standard for the amount of stress manually applied to the tissues. Thus, future studies should objectively quantify the degree of tension imposed by stretching and correlate it with the functional variables. According to Elvey ${ }^{15}$, any inflammatory process affecting a nerve root can lead to the development of fibrous tissue, causing adhesions that result in dysfunction, mobility deficit, and generating pain during movement. Therefore, this would be the reason for treating the nerve with passive movement; however, the therapeutic effect is only explained in general terms, such as preventing the formation of adhesions around the nerve, reducing edema and finding a response of variations in beneficial physiological pressure.

According to Cleland, Hunt and Palmer ${ }^{24}$, if the etiology of symptoms originates from the intra-neural edema, the changes in intra-neural pressure that accompany the neural mobilization may be sufficient to disperse the edema, thus alleviating the hypoxia and reducing the associated symptoms. It could also be directly associated with the immobilization reduction in the neurogenic inflammation. In addition, there is the hypothesis that nerve movement within pain-free variations can help to reduce nerve compression, friction and tension, therefore decreasing its mechanosensitivity. This decrease was seen in the group submitted to neural mobilization given that it regained the pre-lesion values 24 hours after the end of treatment in a similar way to the stretching group when PET at the end of treatment and after 24 hours was compared to the moment after lesion. There was also a significant difference compared to the sham group at the post-lesion moment. Therefore, neural mobilization seems to be a better form of treatment when compared to passive stretching alone. Still, the neural mobilization and the nerve stretching were not effective in decreasing pain immediately after the first treatment session, indicating that the combination of both techniques could produce the desired analgesic effects.

Analyzing the results for a different angle, it is known that one of the consequences of compromised lumbar structures, including sciatica and regardless of origin, is the temporary or permanent reduction in activity, which causes a certain degree of immobility due to lack of use ${ }^{25}$. Coutinho et al. ${ }^{26}$ observed 
that the connective tissue around the soleus muscle of rats submitted to immobilization suffered disorganization of the collagen fibers; and the reduction in the aggregation of state of the collagen bundles caused a decrease in the crystalline characteristics and in the collagen orientation. However, daily stretching after four weeks of immobilization was capable of improving the macromolecular reorganization. Thus, it appears that the effect on the macromolecular organization combined with the variation in intra-neural pressure ${ }^{24}$ may justify the positive results of the neural mobilization compared to static stretching.

It is worth noting that the obtained results are limited by the absence of direct effects on the ischiatic nerve and for the model used in the study (rats). Nevertheless, because the lesion model reproduces the symptomatology found in humans with sciatica $^{17}$, the evaluation model is useful to predict changes in the animals' pain ${ }^{18,19}$, and the therapy adapted for the hind limb of the animals is viable, we concluded that the two forms of therapy were effective in reducing pain and that neural mobilization was more effective. Other limitations of the present study are the need to compare the functional aspects evaluated here and possible histological changes. This approach in future studies may make the results more relevant.

\section{Acknowledgements : :}

To Universidade Estadual do Oeste do Paraná (UNIOESTE) and to Hospital Universitário do Oeste do Paraná (HUOP) for the partial funding of this study.

\section{References $: \because$.}

1. North RB, Kidd DH, Zahurak M, Piantadosi S. Specificity of diagnostic nerve blocks: a prospective, randomized study of sciatica due to lumbosacral spine disease. Pain. 1996;65(1):77-85.

2. Dosani A, Giannoudis PV, Waseem M, Hinsche A, Smith RM. Unusual presentation of sciatica in a 14-year-old girl. Injury. 2004;35(10):1071-2.

3. Rossi P, Cardinalli P, Serrao M, Parisi L, Bianco F, De Bac S. Magnetic resonance imaging findings in piriformis syndrome: a case report. Arch Phys Med Rehabil. 2001;82(4):519-21.

4. Kobayashi S, Yoshizawa H, Yamada S. Pathology of lumbar nerve root compression. Part 2: morphological and immunohistochemical changes of dorsal root ganglion. J Orthop Res. 2004;22(1):180-8.

5. Mannion AF, Denzler R, Dvorak J, Müntener M, Grob D. A randomised controlled trial of post-operative rehabilitation after surgical decompression of the lumbar spine. Eur Spine J. 2007;16(8):1101-17.

6. Henchoz Y, Kai-Lik So A. Exercise and nonspecific low back pain: a literature review. Joint Bone Spine. 2008;75(5):533-9.

7. Rosário JLP, Souza A, Cabral CMN, João SMA, Marques AP. Reeducação postural global e alongamento estático segmentar na melhora da flexibilidade, força muscular e amplitude de movimento: um estudo comparativo. Fisioter Pesq. 2008;15(1):12-8.

8. Rosário JLP, Marques AP, Maluf AS. Aspectos clínicos do alongamento: uma revisão de literatura. Rev Bras Fisioter. 2004;8(1):1-6.

9. Vogt MT, Rubin DA, Palermo L, Christianson L, Kang JD, Nevitt MC, etal. Lumbar spine listhesis in older African American women. Spine J. 2003;3(4):255-61.
10. Pitcher GM, Ritchie J, Henry JL. Nerve constriction in the rat: model of neuropathic, surgical and central pain. Pain. 1999;83(1):37-46.

11. Coppieters MW, Stappaerts KH, Wouters LL, Janssens K. Aberrant protective force generation during neural provocation testing and the effect of treatment in patients with neurogenic cervicobrachial pain. J Manipulative Physiol Ther. 2003;26(2):99-106.

12. Cleland JA, Childs JD, Palmer JA, Eberhart S. Slump stretching in the management of non-radicular low back pain: a pilot clinical trial. Man Ther. 2006;11(4):279-86.

13. Scrimshaw SV, Maher CG. Randomized controlled trial of neural mobilization after spinal surgery. Spine (Phila PA 1976). 2001;26(24):2647-52.

14. Oliveira Junior HF, Teixeira ÁH. Mobilização do sistema nervoso: avaliação e tratamento. Fisioter Mov. 2007;20(3):41-53.

15. Elvey RL. Treatment of arm pain associated with abnormal brachial plexus tension. Aust J Physiother. 1986;32(4):225-30.

16. Andersen ML, D’Almeida V, Ko GM, Kawakami R, Martins PJF, Magalhães LE, et al. Princípios éticos e práticos do uso de animais de experimentação. São Paulo: UNIFESP; 2004.

17. Bennett GJ, Xie YKA. A peripheral mononeuropathy in rat that produces disorders of pain sensation like those seen in man. Pain. 1988; 33:87-107.

18. Tonussi CR, Ferreira SH. Rat knee-joint carrageenin incapacitation test: an objective screen for central and peripheral analgesics. Pain. 1992;48(3):421-7. 
19. Cunha NB, Moesch J, Mallmann JS, Ciena AP, Bertolini GRF. Uso do laser, $670 \mathrm{~nm}$, no quadro álgico de ratos submetidos a modelo experimental de ciatalgia. Rev Bras Med Esporte. 2008;14(2):115-8.

20. Makofsky HW. Coluna vertebral: terapia manual. Rio de Janeiro: Guanabara Koogan; 2006.

21. Hall TM, Elvey RL. Nerve trunk pain: physical diagnosis and treatment. Man Ther. 1999;4(2):63-73.

22. Kikukawa K, Fukunaga K, Kato T, Yamaga M, Miyamoto E, Takagi K. Acute changes in the axonal cytoskeleton after mild stretching of the rat brachial plexus. J Orthop Res. 2003;21(2):359-64.

23. Kobayashi S, Shizu N, Suzuki Y, Asai T, Yoshizawa H. Changes in nerve root motion and intraradicular blood flow during an intraoperative straight-leg-raising test. Spine (Phila Pa 1976). 2003;28(13): 1427-34.

24. Cleland J, Hunt GC, Palmer J. Effectiveness of neural mobilization in the treatment of a patient with lower extremity neurogenic pain: a single-case design. J Man Manip Ther. 2004;12(3):143-52.

25. American College of Sports Medicine. Pesquisas do ACSM para a fisiologia do exercício clínico: afecções musculoesqueléticas, neuromusculares, neoplásicas, imunológicas e hematológicas. Rio de Janeiro: Guanabara Koogan; 2004.

26. Coutinho EL, DeLuca C, Salvini TF, Vidal BC. Bouts of passive stretching after immobilization of the rat soleus muscle increase collagen macromolecular organization and muscle fiber area. Connect Tissue Res. 2006;47(5):278-86. 